\title{
THE BULGARIAN “CHITALISHTE" AS A CENTRE IN SUPPORT OF THE LOCAL ENTREPRENEURSHIP
}

\begin{abstract}
E. Lissichkova*
Knowledge and Reality: Models, Methodology, and Heuristics Department, Institute for the Study of Society and Knowledge, Bulgarian Academy of Sciences, Sofia, Bulgaria

ABSTRACT

Goal: The report presents current trends for stimulating the local communities' entrepreneurship, based on the resources and development potential of the traditional Bulgarian community center Chitalishte. Method: The report is based on its own empirical materials, which shows the Chitalishte as a: factor for social capital, channel for building entrepreneurial attitude, and incentive for new economic activities. The systemic and scientific approaches and the theory of self-organization are applied. The natural environment of different communities is studied as well as the external targeted impact on the community processes. The report presents the contemporary Chitalishte as a community center, influencing positively on the entrepreneurial motivation and stimulating the individuals' autonomy. Results: The main functions of the Chitalishte are described as: Communication - a meeting point and place to share experience; Information - a treasury of the local memory for traditional productions, livelihoods and practices; Openness and accessibility; mediation between the local community and globalization. Thus, it manages to create entrepreneurial attitudes in the field of tourism, craftsmanship, agriculture, social entrepreneurship, tangible and intangible cultural heritage. Conclusions: The Chitalishte today has the potential to fill in niches in the field of communication, information, training, motivation and innovation in support of local business.
\end{abstract}

Key words: community, Chitalishte, entrepreneurships, partnerships, mediation, resource, development.

\section{INTRODUCTION}

The entrepreneurship is a phenomenon of the social development. It is a complex one and is the result of many successive and synchronous processes, including personal characteristics of the individual. In the context of this study, we will focus on the entrepreneurship as a process with multiple impacts on the socio-cultural and economic development of the community, revealing opportunities for the development and forming attitudes and motivation to change the economic activity of individuals in this community. We consider entrepreneurship as a process since we distinguish different phases that the individual goes through while realizing his innovative intentions. The entrepreneurship is also a process impacted by the pressure of the dynamics of modern information and communication environment, which necessitates continuous correction and reconciliation of source data, modernization of

\footnotetext{
*Correspondence to: Emilia Lissichkova, Street address: "Krasno selo" Res. Complex, 195 Block, entr. III, floor 5, flat 73, Postcode, City: 1618 Sofia, Bulgaria, Phone: (+359 89) 66692 01, E-mail: e.lissichkova@agora-bg.org
}

the approaches, the ever more pressing need for new knowledge, which, in the modern economic environment, are the main resources for enterprising behaviour. These two factors the modern information and communication technologies (ICT) and the knowledge-based economy form the entrepreneurial environment, bringing new players into the local development alongside local businesses and local government structures. Among them, along with local and regional media, regional development agencies, non-governmental organizations, informal unions, consultancy firms, etc., in the recent years the contemporary community centre has found its place and role. Among them is the traditional for Bulgaria community cultural center called Chitalishte. From the point of view of the mass culture of the Bulgarian Chitalishte as a "Cultural institution for the dissemination of knowledge and culture, especially active during the Renaissance" (1), the link with entrepreneurship seems unjustified. In the context of this study, we will look at this organization in terms of its advantages, thanks to which the Chitalishte as an institution can significantly influence the formation of an 
environment for stimulating local entrepreneurship. These advantages include the prominent community character, the wide territorial presence in each settlement, the availability of own materials and human resources, the state's financial support, the availability of a library as a traditional information centre, the legitimacy of the Chitalishte, etc. Particularly important is the fact that the trust in the Chitalishte has been preserved, which, recently, stands out more strongly.

\section{METHODOLOGY AND RESEARCH TECHNIQUES}

The presented results are based on our own empirical materials. The subject of the study is the Chitalishte with its functions related to the formation of the social capital of the community, its ability to be a channel for building entrepreneurial attitudes, introduction of social innovations and an incentive for new economic activity on local level. In the study, we have applied the systemic, scholarly approach and the theory of self-organization. The empirical information is collected through sociological techniques, the selected profile of the participants in the survey aims to involve representatives of all social groups on local level: the local businesses, people working in Chitalishte, local administration, youth, unemployed, NGOs, and others. The empirical study covers more than 10 years of field work in different regions of Bulgaria, including observations in more than 70 communities, the access to these being the local Chitalishte. We have studied the natural environment in the local communities and their interactions with various external factors. The change of the role of the traditional Chitalishte in a created new environment for functioning through an externally targeted impact on the community processes was also studied. The results obtained are the basis of the presented concept of the contemporary Chitalishte as a community centre, positively influencing the creation of motivation for entrepreneurship in the local population, stimulating the autonomy of the individuals and releasing their potential. The emphasis is on revealing the potential of the modern community centre as an initiator of social innovation by mobilizing the potential of the population to improve their lifestyle.

Prerequisites for the formation of entrepreneurial behaviour

The factors, influencing the entrepreneurial attitudes, are numerous and, depending on the specificities of a particular place, can influence to varying degrees and in a different way. The socio-economic environment that outlines the trends for the development based on local resource, the availability of local successful or unsuccessful models and practices and the specificities of the local policies and traditions is critical. The environment supporting entrepreneurship is based on several factors: administrative reliefs in the municipality and incentives to small and medium-sized businesses especially in the agricultural areas, qualified human resources, good infrastructure - roads, access to quality internet, good coverage of mobile operators, availability of recreation areas and educational institutions for children and students. The environment has a decisive negative impact on the more remote and peripheral territories, which are systematically depopulated and their economy is dwindling. Indeed, in the recent years, many municipalities in Bulgaria managed to attract significant investments to build local production capacities. For example, in the municipality of Montana, about 40 SMEs successfully operate today with a different scope of activity. (2) Thanks to foreign investments, new metalworking industries are being built, with 300 new jobs open. At the same time, "a major problem for businesses is finding skilled workers. Businesses cannot meet their workforce needs, which affects their development. The policy of most enterprises is to deliberately limit production due to lack of workforce." (3) In many of the municipalities in Bulgaria, there are natural and culturalhistorical resources, which are a prerequisite for the development of tourism. There is an extraordinary "hidden" tourist potential that, if faced with entrepreneurial behaviour and innovative approaches, could reveal new opportunities for local livelihoods and living conditions.

Another factor for the formation of an entrepreneurial behaviour is the "health status" of the local community. In a healthy territorial community with well-built horizontal and vertical links, the attitudes to entrepreneurship are formed spontaneously. Accordingly, in communities with a disrupted demographic structure, mixed ethnic communities or depopulation, the local entrepreneurship is severely restricted or subject to external business interests. The topic of motivation for entrepreneurial behaviour is especially relevant to young people, seeking initial realization in the community. On the other hand, in these territories and communities, the percentage of young people who are neither educated nor qualified or working is the highest. The jobs that are offered are usually for the low-skilled people, with low income and are unattractive 
to young people. This creates attitudes towards migration and realization abroad or in the larger city. At the same time, in recent years, the opposite trend has been observed - young people with education and qualification settle in smaller settlements or villages near the towns (e.g. Verinsko village, Ihtiman Municipality, the village of Nikolovo, Montana Municipality). They form modern communities, based on the new ICT culture. Their main characteristic is the entrepreneurial ability to build their lifestyle according to their needs - professional realization and achievement of a good standard and environmentally friendly life.

Overcoming inertia, the utilitarian attitudes and lack of motivation for entrepreneurship and self-employment is an important issue for the revitalization of territories and the introduction of innovations in local production. The community-based entrepreneurship incentives, based on a reassessment of local assets and potential, create prerequisites for pooling and complementing the resources of individuals, creating a community-shared vision for local development, and reducing the risk to the individual entrepreneur. This extends his choice and decision-making, enriches ideas and assists in its realization in the interest of public and private benefit.

The community incentives for entrepreneurship are linked to the community leadership. It influences the entrepreneurial attitudes through their characteristics to form attitudes, to set trends for development on a value basis, to find the balance between the interests of the individual and the public interest. In this context, the role of the Chitalishte is highlighted. This is the role most closely linked to the value system of the community, which carries the mark of unifying its individual fragments.

\section{RESULTS}

The influence of a Chitalishte on the creation of an environment, stimulating entrepreneurship is based on its presence as one of the main institutions of the community. "Its main comparative advantages consist in its ability to mobilize the existing human potential, and its flexibility and capacity to work with limited time and resources in various fields." ... "In the Chitalishte, the community is no longer perceived as a sociological abstraction but is transformed into a reality of human experiences. It is a place where people exchange their personal knowledge, share their worries and receive advice and support." (4) It has an irreplaceable role in the self-organization of the community, based on its central character. With developed community-based capacity, the Chitalishte may have a significant impact on the opening and development of local resources for private entrepreneurship. Its advantage as a community institution is that it has no private interest in doing such activities. It works in the public interest and provides access to all people to the opportunities it provides. This distinguishes it from the business structures and, at the same time, makes it a good partner in the processes of local development and revitalization of the territory. In the light of the local entrepreneurship, the Chitalishte can be seen from two different angles: on the one hand, it is a resource for local development and must build on its functionality as a resource centre and on the other hand - as a connecting point for local entrepreneurs and producers to access opportunities and resources and to strengthen the horizontal links in the community, creating an entrepreneurial environment.

\section{Chitalishte - Resource Centre}

This functionality is based on the traditional characteristics of the Chitalishte as the information and communication centre of the local community. In most cases, the Chitalishte is the home of the public library, which is the only one in the smaller settlements. Thanks to it, the Chitalishte satisfies the right of the community to be informed, to have access to knowledge, to be able to make informed choices, to be a part of the information society. Nowadays, in most reading rooms of the Chitalishte libraries, open-access computer rooms have been created and continue to be created, and previous readers are already Internet users. The availability of information is a source of opportunities and access to good practices and resources for innovation. In some places, the Chitalishte has found a niche for its activity, namely to connect the creators of science-intensive products with their users on the spot.

A stimulus for entrepreneurship is its character as a centre, a neutral territory for communication and socialization among enterprising people in the community. Because of the competitive environment and the shortage of time, business people find it harder to share their interests. "In the conversations with the entrepreneurs in Ihtiman, the assessment of the fragmentation of social ties and the lack of solidarity prevails for the fact, that everyone takes care of his own interests and nothing can be done jointly."(5) This is also evident from the small number of 
producer groups that have applied for the measure $142 \quad$ "Establishment of produceres'organizations"of the RDP 2007 2014. Sharing a common vision for development and reaching an agreement on common interests requires several conditions that the local Chitalishte can provide. These include neutral territory, neutral mediation, positive communication environment, logistics and regularity of meetings, lack of personal interest in the discussions. Sharing a common vision for the development of the region between entrepreneurs, local authorities, civic associations and other stakeholders with the mediation of the Chitalishte leads to a consensus among the parties on the direction, trends, and participation of everyone, supplementing the local resources and longterm planning. The power of the Chitalishte is in the development of horizontal links in the community, which is of utmost importance for the creation of entrepreneurial attitudes based on a shared vision for local development. The results of the survey show that these links, building the social capital of the community, can not be stimulated either by the municipal administration with its vertical and hierarchical relations or by the local business. It is well known that horizontal links within a community are a resource for development. (6) The active association of individuals and groups of people into a community, based on shared interests, opens up additional space for personal expression and individual prosperity that underpins the entrepreneurial attitudes. The entrepreneurial approach creates prerequisites for pooling and supplementing the resources of individuals, for developing a community-shared vision for the development of settlement and reducing the risk for the individual entrepreneurs. This extends their opportunities of choice and decision-making, enriches the ideas and assists in their realization in the public or private interest. "The community development is very similar to entrepreneurship." (7) It enables us to see the opportunities that the environment finds in a new way, preserving the existing ones and turning these into a resource for development. This is based on the concept of sustainable local development. Within 2009-2017, the Chitalishte in the village of Kurtovo Konare (Stamboliiski municipality), turning into a place for discussion on the problems of the community, found the intersection of the common interest of the local farmers, local authorities, small family farms and the institutions in the village, which led to a series of innovative steps in supporting the local livelihood in vegetable production. The practice has shown that the Chitalishte has all the characteristics of a resource centre and a medium for communication and experience sharing, a local memory storehouse for traditional productions, livelihoods, and practices as a stimulus for innovation.

Chitalishte and local human resources

This is a characteristic, based on another traditional activity of the Bulgarian Chitalishte - informal supplementary education for children and adults. The relationship between the degree of qualification and the formation of entrepreneurial attitudes is logical. Improving the quality of human resources in the community is related to the acquisition of competencies, reliability, and attitudes to change. The involvement of some Chitalishte with activities aimed at raising the qualification and the skills for employment is based on the availability and potential of the Chitalishte in realizing their new social role as a social mediator for development and validation of new forms of training and employment among the population in the new economic and social conditions. This presumably fills the gap between the existing available educational and qualification local resources and the development prospects of the region, based on the actual resources and the specific initiatives of the population for realization on the labour market and income provision. The grounds of such a commitment of the Chitalishte is in its historical and organizational development and directly corresponds to the European policies for lifelong learning, preparation, and requalification for alternative employment, a compulsory prerequisite for inclusion in the knowledge-based economy. On the other hand, due to its specificity of community organization and trust-based relationships, it can contribute to forming a culture of partnership and positive competition, motivation and entrepreneurial attitudes based on new knowledge and skills. The potential of the Chitalishte to improve the quality of human resources in the community is manifested in its ability to determine the needs of training the population according to its level of education and professional qualification, according to the available and potential resources in the region to start new work activities; to motivate people to learn as an element of the continuous vocational training system; to organize and conduct training courses; to draw up curricula; to provide the necessary facilities for conducting the training; to promote courses among the population and employers in the region in order to find work for successful 
graduates. For example, the Chitalishte in Novo Selo (Vidin District), Radilovo (Peshtera Municipality), Kurtovo Konare (Stamboliiski Municipality, Brestovitsa village (Rodopi Municipality), etc. regularly provide local farmers with short courses on farming practices and presentations of the current requirements for growing crops, information on funding opportunities and access to resources, improving the production environment of local producers by investing in search, certification, research of qualities and popularization of old local varieties that expand the sphere of activity of local producers and improve their access to customers. In most cases, the Chitalishte organizes short-term training courses - from 45 hours to 150 hours, focusing mainly on acquiring key competences - the new information technologies, as well as new information about alternative forms of employment, training in traditional crafts, production of agricultural products, and other services and products, for which there is a potential market. It is not necessary for the Chitalishte to be a provider of training services, its more important role is to be a successful mediator between the population and the training institutions and experts. In the presence of a well-functioning connection of the Chitalishte with the local authorities and the business, the courses are in conformity with the potential demand of qualifications for the labor market and training courses can be organized in partnership with educational institutions and potential employers. The basis of such a training activity is the formation of entrepreneurial behaviour, initiative, and partnership culture. In this segment of the activities of the Chitalishte, we have pointed out the targeted work with young people to form entrepreneurial attitudes. The Chitalishte seek different forms of motivation of young people, including meetings-discussions of young people with successful local people, as well as joint activities to form motivation for change, innovative thinking and entrepreneurial behaviour to improve personal development strategies of young people on spot.

Partnership with business

The characteristics of the local Chitalishte make it a reliable partner of the local business. This is true especially of areas such as tourism. With adequate municipal tourism development strategies, local traditions and cultural and historical heritage, preserved by the local Chitalishte are a specific resource. Besides the more traditional inclusion of the intangible cultural heritage in the tourist attractions of local tour operators, there are successful practices of tourist centers, established in the Chitalishte (the villages of Momchilovtsi, Smolyan Municipality, Gara Bov, Svoge Municipality), developing new local tourist packages, providing information and advertising activities to the local tourism, attracting foreign tour operators. There are cases of courses for mountain guides, organized by the Chitalishte (the village of Gara Bov). Some of the Chitalishte, develop new tourist attractions and sites, based on the local tourist potential. One example is the developed "Tornal e Todu" eco-trail in the village of Momchilovtsi - one of the most visited eco-trails in the region, developed on the idea of the community and with the coordination of the local Chitalishte. Another example of activities, organized by Chitalishte in support of local entrepreneurs are the culinary festivals. Examples are the "Thrace Culinary Heritage" Festival in Ivaylovgrad, "Tastes from Banat" Festival in Asenovo, Nikopol Municipality, the "Festival of keşkek" in the village of Radilovo, Peshtera Municipality, etc. which have been monitored in recent years. The culinary festivals are mostly tourist attractions, helping local hoteliers, restaurateurs, owners of guesthouses, producers of agricultural products. Preserving and giving market value to local crafts is also a resource with a tourism potential. Chitalishte such as "Elin Pelin" in the town of Elin Pelin, "St. St. Cyril and Methodius", in the town of Silistra, in the last years made workshops for making folklore costumes, in the villages of Radilovo and Telish there are courses for weaving on horizontal and vertical handloom, a carpet workshop exists at the "Prosveta" Chitalishte in Malko Tarnovo. In most cases, schools for children and teenagers have been created to transfer skills of different traditional crafts. In Kurtovo Konare there is a children's school for plastic sculptures made of maize leaves for making dolls, icons and souvenirs, reviving traditional handicraft practices from plant materials. Thanks to their activity, the souvenirs made of maize leaves became extremely popular, including in the UNESCO headquarters in Paris. These souvenirs are made by order and have market value. In many settlements, mainly with culinary festivals, culinary workshops are held to preserve and transmit the local culinary traditions between generations. Last but not least, the Chitalishte can be considered as a local resource for the entertainment business. There are cases where local folklore or other art formations, organized by the Chitalishte, are hired by the 
local business to present entertainment programs to tourists and guests.

All this makes the Chitalishte an information bank and an archive of local practices - craft, agricultural, storing the history of local productions, restoring old varieties, solving problems, searching for and affirming enterprising local people and their contribution to local development. The pragmatic interpretation of this regional study function for exploring, collecting, archiving and promoting the local traditions and culture, and providing free access to this information is an incentive for entrepreneurial behaviour.

The Chitalishte is a territory for social innovations. There are cases of communitybased demonstration practices based on community innovations, forming attitudes to experimentation, individual activity and creating successful entrepreneurial models, provoking activity among certain community environments.

\section{The New Chitalishte of Challenges}

In the public space, the Chitalishte is mainly seen as the local cultural institution, called upon to preserve and develop the traditional culture and information resources of the community. Due to one of the main features of the Chitalishte as sustainable local structures with a long history, they represent a projection of the past, present and future of their community. For this reason, the preservation of local tradition and traditional culture is only one of the aspects of the contemporary community center, which is a retrospective of the past of the community. The dynamics of the present and the challenges of the future inevitably require a change in the traditional understanding of the Chitalishte. The modern community moves from processes, based on modern ICT and the knowledge economy, which leads to rethinking the role of the modern community centre and its functionality. The closure of a public resource such as the Chitalishte with its assets, traditions, and experience only in the sphere of preservation of the traditional culture and memory gives it a museum value, which would greatly limit its benefits to the community. The targeted impact of the environment on activating new functions of the Chitalishte has shown that this institution has hidden potential to become an active actor for local economic and social development. Without losing its traditional functions, it can efficiently upgrade its functionality in the light of changing needs and following the community agenda. Investing in the communal nature of the Chitalishte, in its ability to create an effective environment for communication and community communication, and to provide access to topical knowledge, gives it a characteristic of a required factor for the formation of local entrepreneurial attitudes and the creation of an environment stimulating the local business.

For most Chitalishte, this is still an unattainable task. Along with the limitations of cultural policies, the Chitalishte suffers from conservatism and self-censorship that prevent them from fully developing their entrepreneurial potential and building autonomous behaviour towards community needs. Nevertheless, the observed practices and the analysis of the above-described characteristics give enough reason to present the Bulgarian Chitalishte as a local resource in support of local entrepreneurship. In this role, the following main functions are distinguished: Community moderator: In this function, it creates the conditions for intensive exchanges between active local players, creates an environment for contacts between local authorities and businesses, between business representatives themselves, between employers and potential workers. It creates a positive environment for dialogue between partners to engage in economic activities based on shared values. It supports but also shapes entrepreneurship as a value in their community. Chitalishte cannot be experts in business and entrepreneurship, they lack the necessary qualifications and human resources of specialists but have the resource to be the moderator of the dialogue among the main factors for building a stimulating entrepreneurship environment.

Mediator: There is already enough experience in the Chitalishtes, confirming the role of the Chitalishte as a mediator. Unlike the role of the moderator, that achieves consensus and complementarity of interests in the community, its role as a mediator is to facilitate the linkages and relationships. This role places the Chitalishte in the position of a link between two active points, of a channel through which they connect, a transmission system for information, services and resources. Part of the new functions that the Chitalishte develops in this role are providing up-to-date information with modern information tools, providing a local access channel to the global space. The mediation as a community center role is observed in different formats. For the Chitalishte in the villages, this is the function of an information mediator, providing access of the local population to the institutions in the municipal or district centers as a transmission system of services and information from the 
institutions to the local person and vice versa. This includes filling in applications, administrative documents, farmers' applications for state aid, and, on the other hand, finding, structuring and providing information on funding, aids, changes in the requirements of one or another institution in relation to administrative services or requirements. Another form of mediation is providing information and access to new products and services on the local market, providing consultations and meetings with experts or companies in support of local producers. The role of a social mediator - to attract and involve the population in the development and implementation of regional strategies and policies and their realization is particularly important nowadays. The Chitalishte has the capacity to integrate specific social groups in society, motivating them for professional and social realization, which makes the Chitalishte an effective mediator of local and state authorities and business, in solving community problems.

Partner: Chitalishte begins to evaluate its own capabilities and resources, comparable to those of other local actors, and to enter into partnerships from the point of view of their specific competencies and skills. Social Innovation provides good conditions for the majority of the Chitalishte involved in the study to share the good ideas and initiatives of other local organizations and to become partners. The partnership role of the Chitalishte is preferred in the implementation of largescale local development projects, or simply because of the importance of the idea. This partnership-building process is already being implemented by some community centers, cooperating with local policies and participating in various local "development coalitions" (the Chitalishte in Plachkovtsi, Lyaskovets, Karlovo, Dryanovo are members of the Local Action Groups, working and consulting Groups to committees of municipal councils, actively participate in municipal forums, largescale municipal projects). "The Chitalishte has become a preferred partner for municipalities as well as NGOs" - the secretary of "Hadji Nencho Palaveev" Chitalishte, town of Koprivshtitsa said. However, we have to say that the preferred partner is the Chitalishte, which has a long-term vision for its development, actively interacts with different community groups, enjoys the trust of local people, has its own materials and human resources, has experience in project management and works with volunteers.

\section{CONCLUSIONS}

In conclusion, we can summarize that the Chitalishte now has the potential to fill in niches in the communication, information, training, motivation, and innovation of local businesses, with sufficient supporting local and national policies for building its capacity in this direction. It is a factor in building an environment that stimulates local entrepreneurship and is a resource for the revitalization of the territory. The Chitalishte contains the undeveloped potential for developing local communities to improve the lifestyle of the population.

\section{REFERENCES}

1. A Dictionary of the Bulgarian Language

2. Municipal Plan for development of the municipality of Montana, $2014-2020$

3. Staykova, R., Analysis and assessment of the municipality potential for development of activities, related to the alternative tourism, social entrepreneurship, arts and culture as well as the cultural and historical heritage, Municipality of Montana, 2016 Own information

4. Gavrilova, R., Daskalova, K., Alexandrov, H., Kirilov, I., Chichek, R., Emilia Lissichkova, The Bulgarian Chitalishte past, present and future, Sofia, 2000

5. Tilkidzhie,v N., Kelyan. M., Kolev,a G., Stoilova, R., The peripheral municipality: local development resources, Sofia 2000

6. Alexandrov, H., Kirilov, I., Chichek, R., Community development, Sofia, 2003

7. Alexandrov, H., Kirilov, I., Chichek, R., Community development, Sofia, 2003 